\author{
Lawrence Livermore National Laboratory \\ Livermore, CA 94550
}

\title{
ABSTRACT
}

Analysis of oxygen on beryllium can be routinely performed using heliumion backscattering (RBS). However, determination of the bulk oxygen concentration by this technique is limited to about 350 atomic parts per million (appm). We have performed simultaneous RBS and particle-induced $x$-ray emission ( $P I X E$ ) measurements to improve the detection limit for bulk oxygen. The RBS measurements allowed determination of the surface oxygen before and after in.situ sputtar cleaning by argon ions in an ultra-high-vacuum system. PixE measurements of specimens with surfaces maintained clean by sputtering permitted assessment of the concentration of oxygen in the bulk. For our geometry and detector sensitivities, 90 percent of the oxygen $x$-ray signal originated in the first $2.1 \mu \mathrm{m}$ of the beryllium and a detection limit of 10 appm was found.

* Wark performed under the auspices of the U. S. Department of Energy by the Lawrence I.ivermore National Laboratory under contract namber W-7405-ENG-48. 


\title{
INTRODUCTION
}

We have investigated the application of simultaneous Rutherford backscattering (RES) and particle induced $x$-ray emission (PIXE) measurements [1] for the analysis of oxygen on and in beryllium. The measurement goals were to determine surface oxygen with a detection limit of a few times $10^{14}$ oxygen atoms $/ \mathrm{cm}^{2}$ and bulk oxygen with a sensitivity approaching len appm in a volume large enough to be represertative of the bulk.

The RBS measurements gave the surface oxygen before and after in-situ sputter cleaning by argon ions in an ultra-high-vacuum system. PIXE from surfaces being maintained clean by the argon ions permitted assessment of the concentration of oxygen in the bulk. Simultaneous measurements ensured identical surface conditions for the RBS and PIXE spectra. Since the RBS results are quantitative and the PIXE results can be directly related 10 an analytical calculation without any unknown parameters, this combined dpproach is quantitative. Another important aspect of this measurement is the relatively large are $\left(\sim 5 \times 5 \mathrm{~mm}^{2}\right)$ sampled, which should correctly assess the area-averaged amounts of oxygen in solution and in BeO particulates. Finally, this approach is basically non-destructive because (1) only the surface oxide need be removed for the highest-precision analysis, and (2) lawer-precision measurements can be made without removing the surface oxide. To our knowledge there is no other measurement procedure that meets the measurement goals.

\author{
CALCULATION OF HELIUM-INOUCED O(K) X-RAYS
}

The RBS determination of the oxygen surface density on beryllium from 
the ratio of the net counts under the oxygen surface peak to the height of the beryllium edge, corrected by appropriate scattering and stopping crosssections, rollowed standard calculational procedures [2]. Consequently, this determination needs no further discussion. In contrast, a brief description of the calculation of the helium-induced $O(K) X$-rays based on the measurement geometry shown in Fig. 1. will be presented.

For the surface oxide, the relevant equations have been previously published [3]. In particular, for oxides thin mough for the assumption of uniform $x$-ray production throughout the oxide and negligible $x$-ray absorption, the relevant equation for the detected $0(k) x$-ray intensity $I_{\text {DS }}$ per $10^{15}$ oxygen atoms $/ \mathrm{cm}^{2}$ per $100 \mu \mathrm{C}$ of $2 \mathrm{MeV} \mathrm{He}{ }^{+}$can be written as

$$
I_{0 S}=6.24 \times 10^{29} \varepsilon_{0} \omega_{k} \sigma_{j}(2 M e V) d \Omega / 4 \pi,
$$

wheri $\epsilon_{0}$ is the overall detection efficjency for $O(K) X$-rays, $\omega_{k}$ is the fluorescence yield for $0(K), \sigma_{i}(2 H e V)$ is the oxygen $K$-shell ionization cross section $\left(; i^{2}\right)$ for the incident $2 \mathrm{HeV}$ helium ions, and $d \Omega / 4 \pi$ is the fractional solid angle subtended by the $X$-ray detector. Estimating the si(Li) detector constant $C_{d}=c_{0} d \Omega / 4 \pi$ to be $7 \times 10^{-7}$, using $\omega_{k}=7.7 \times 10^{-3}[4]$, and using $\sigma_{i}=9.121 \times 10^{-19} \mathrm{~cm}^{2}[5]$, we calculated that IOS would be $2.22 \times 10^{4} \mathrm{O}(\mathrm{K}) / 700 \mu \mathrm{C}$ for $10 \AA$ of Be0 with a density of $3.01 \mathrm{~g} / \mathrm{cm}^{2}$. Considering the tabulated $\sigma_{j}(E)$ values given by Cohen and Harrigan [5] and Ziegler's dE/dx values [6], Eq. (1) holds (within two percent) for Be0 thicknesses below 160 \&

Considar beryllium, with a clean surface, that is pure enough to permit use of the mass absorption coefficients and stopping powers for pure berylitum. 
For this initial calculation, assume that the concentration of oxygen is not a function of depth; this assumption should be very good for beryllium after removal of a considerable amount of surface material. The signal from oxygen in the bulk was calculated using step-wise integration of the contributions of each thickness interval ax of fig. 1. For each ox at a depth $x$, the contribution to the detected signal per 1 appm per $100 \mu \mathrm{C}$ of helium ions can be written as

$$
d]_{B B}=7.71 \times 10^{27}{ }^{c}{ }_{0} \omega_{k} \sigma_{i}[E(x)] \exp \left[-10^{-4} \mu x / \cos \left(34^{\circ}\right)\right]_{4 \pi}^{d} d x \text {, }
$$

where the units of $x$ and $d x$ are $\mu \mathrm{m}, \mu=3920 \mathrm{~cm}^{2} / \mathrm{g}$ [7] is the mass absorption coefficient of $O(K) X$-rays in beryllium, and the constant includes the atomic density of 1 appm oxygen in beryllium, the number of ions in $100 \mathrm{sC}$, and the conversion of $\mu \mathrm{m}$ to $\mathrm{cm}$. With $\mathrm{dx}=0.0115 \mathrm{\mu m}$, the calculation yielded $I_{D B}=37.4 \mathrm{D}(\mathrm{K}) /\left(\mathrm{appm} \cdot 100_{\mu} \mathrm{C}\right)$. The stepwise integration also showed that $5 \mathrm{~J}, 90$, and 95 percent of the oxygen $X$-ray signal originate, respectively, ir the first $0.66,2.1$, and 2.6 win of the beryllium.

Comparing this result for bulk oxygen to that found above for a surface oxide, ?eads to the conclusion that the $O(K) X$-ray signal from 10 \& of Surface Be0 would be equivalent to that from about $600 \mathrm{appm}$ of oxygen in the bulk. Therefore, high precision determination of the bulk oxygen level requires that the surface oxide be reduced to a negligible average thickness. The signat from $0.33 \mathrm{~A}$ of surface $8 \mathrm{eO}\left(\mathrm{i} . \mathrm{e} ., 2.4 \times 10^{14} \mathrm{O} / \mathrm{cm}^{2}\right.$ ) would equal that from 20 appm of oxygen in the bulk. These considerations were the basis for the requirement of in-situ sputter cleaning of the beryilium surface during simultaneous RBS and PIXE measurements. 


\section{EXPERIMENTAL CONSIDERATIONS}

The measurements were made in an ultra-high-vacuum (UHV) chamber to minimize re-oxidation of the beryllium surfaces during sputtering. ultra-high purity beryllium specimens were obtained from a commercial supplier [8]. They were chemically etched to remove any thick oxides, oxygen concentration profiles, and other surface contaminates. After etching, specimen \#29A was exposed to laboratory air for more than six months before the as-received measurements were made.

The helium jons were generated by a Penning ion source and accelerated by a 3 MV van de Graaff accelerator. Visual observation of the helium beam (1ypical current of $50 \mathrm{nA}$ ) on a phosphor screen at the target position showed that the beam was slightly less than $5 \times 5 \mathrm{~cm}^{2}$. A differentially pumped $5 \mathrm{kV}$ ion gun provided the argon ions for sputtering. He used $3.25 \mathrm{keV} \mathrm{Ar}^{+}$ions (typical current of $5 \mu \mathrm{A}$ ) because this was the maximum energy, consistent with the available electronic raster, to achieve a clean spot of approximately $5 \times 5 \mathrm{~mm}^{2}$ at the target position.

Backscattered helium particles were analyzed using a UHV-compatible, ion-implaated silicon detector at room temperature [9]. Detection of the PIXE spectrum was accomplished using an ultra-thin-windowed Si(Li) detector having a compact magnetic deflection unit for removal of the backscattered ions from the $x$-ray axis $[10]$.

The high-precision measurement procedure consisted of simultaneous RBS and P1Xt. measurements for three different specimen conditions: (1) as-received condition using accurate current integration of the helium beam, (2) after removal of the surface oxygen, but during continuous argon-ion sputtering to 
maintain the cleanliness, and (3) after sputter removal of various amounts beryllium, but during argon-ion sputtering.

RESIILIS AND DISCUSSION

Fig. 2 shows the relevant part of the RBS spectro of beryllium \#29A for both the as-received and sputter.cleaned conditions. The initial surface oxygen level was deternined to be $1.4 \times 10^{16} 0 / \mathrm{cm}^{2}$ (i.e., about $19 \AA$ of Be0), and the spectrum far the cleaned surface displayed no signs af surface oxygen. However, the three-sigma value for the background counts at the position of the oxygen peak sets the maximum amount of surface oxygen an the cleaned surface to less than $4 \times 10^{14} \mathrm{O} / \mathrm{cm}^{2}$.

The DIXE spectra displayed in Fig. 3 correspond to the as-received and sputter-cleaned RBS spectra of Fig. 2. Determination of the net $D(K)$ counts required the subtraction of the bremsstrahlung background frori each spectrum. The sinape of this background was obtained by a spectrum stripping procedure. 1here was a large dip in the bremsstrahlung spectrum corresponding to absorption by the oxyger ( $K$ edge) in the ice layer on the entrance surface of the $\operatorname{Si}(L i)$ detector. This effect has been describet previously [11].

We determined the $S t(L i)$ detector canstant $C_{d}$ by comparing the measured change in the net $O(K)$ signal for the measured change in the surface oxygen level (as determined by RBS) with the values caiculated by ta.(1). By this procedure $c_{d}$ was found to equal $1.24 \times 10^{-6}$ instead of the estimated $7 \times 10^{-7}$ value used above in the calculation section. Thus, the calculat.ed, detected $O(K)$ yield from the bulk, $\mathrm{I}_{\mathrm{OB}}$, becomes $68.1 \mathrm{O}(\mathrm{K}) /\left(\mathrm{appm} \cdot 70 \mathrm{O}_{\mu} \mathrm{C}\right)$. this yalue was used to determine the oxygen concentration in the bulk Irom the $-6-$ 
measured, net $0(K)$ yieid. For the sputter-cleaned spectrum of $\mathbf{F}: \mathbf{g}$. 3 , the bulk axygen concentration was found to be 220 appm. The minimum detectable level was calculated from the three-sigma value of the background counts under the $O(K)$ peak to be 10 appm.

The sputtering yield for $3.25 \mathrm{keV}$ argon ions incident at 30 degrees from the normal can be estimaled to be $1.5 \mathrm{Be} / \mathrm{Ar}[12]$. Once the surface was clean, the $O(K)$ yieid from the bulk was constant within the statistics of the measurement (i.e., within about ten percent) for removal of up to 0.18 ym of beryllium. This supports the assumption that the bulk oxygen concentration was independent of depth because we are most sensitive to oxygen near the surface.

CONCLIJOING REMARKS

We have demonstrated high-sensitivity analysis of oxygen on and in berylitum using simultaneous PBS and PIXE measurements. The novel aspect was the detection and use of the helium-induced $O(K) X$-rays for determination of the bulk oxygen concentrations in a representative volume of beryllium with a detection limit of about $10 \mathrm{appm}$. We have used this quantitative approach to nheasure oxygen in beryllium at concentrations between 170 and 3600 appm.

$1 \mathrm{~L}$ is a pleasure to acknowledge 5 . J. Holmes and J. R. Thournir for their able technical assistance in the experimental aspects of this work, F. Fulton for supplying the etched beryllium, and A. Toor for his initial and continuing support of this analysis method. 


\section{REFERENCES}

[1] R.G. Husket, Nuc ]. Inst., and Meth. 218 (1983) 420.

[2] W.K. Chu, J.W. Mayer, and M.A. Nicolet, Backscattering Spectrometry (Academic Press, New York, 1978).

[3] R.G. Musket and W. Bauer, J. App 7. Phys. 43 (1972) 4786.

[4] J.O. Garcia, R.J. Fortner, and T.M. Kavanagh, Rev. Mod. Phys, 45 (1973) 171.

[5] D.D. Cuhen and M. Harrigan, Atomic Data and Nuclear Data Tables 33 (1985) 255 .

[6] J.F. Ziegler, Helium Stopping Powers and Ranges in All Elements (Pergamon Press, New York, 1978).

[1] B.L. Henke, P. Lee, T.J. Tanaka, R.L. Shimabukura, and B.K. Fujikawa, Atcmic Data and Nuciear Datd Tables 27 (1982) 1.

[B] Eiectrofusion, Fremont, CA

[9] J. Kemmer, P. Burger, R. Henck, and E. Heijne, IEEE Trans. Nuc 1. Sci. NS29 (1982) 733 .

[10] R.G. Musket, Nuc 1. Instr, and Meth. B15 (1986) 735.

[11] R.G. Musket, in Proc. Workshop on Energy Dispersive $X$-ray Spectrometry, National Bureau of Standards Spec. Publ. 604 (NBS, MD, 1981), p.97.

[12] H.H. Andersen and H.L. Bay, In Sputtering by Particle Bombardment 1 , R. Behrisch, ed. (Springer-Verlag, New Yark, 1981), p.145. 


\section{Figure Captions}

Fig. 1 Schematic of measurement arrangement

Fig. 2 Helium-ion backscattering spectra for Be\#29A in the as-received and sputter-cleaned conditions

Fig. 3 Helium-ion induced $x$-ray spectra for Be\#29A obtained simultaneously with the backscattering spectra of Fig. 2 . 


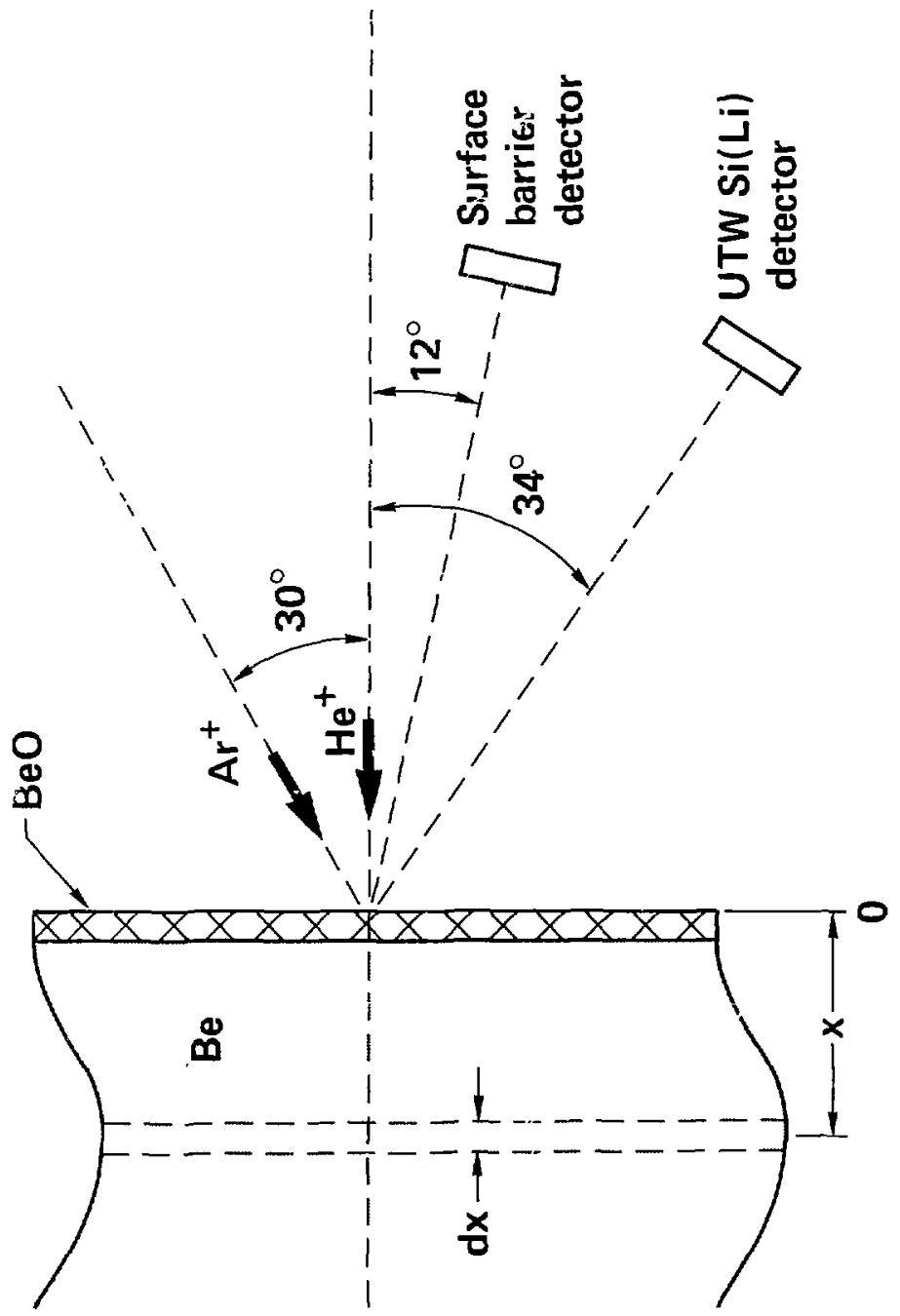

Fig. 1 


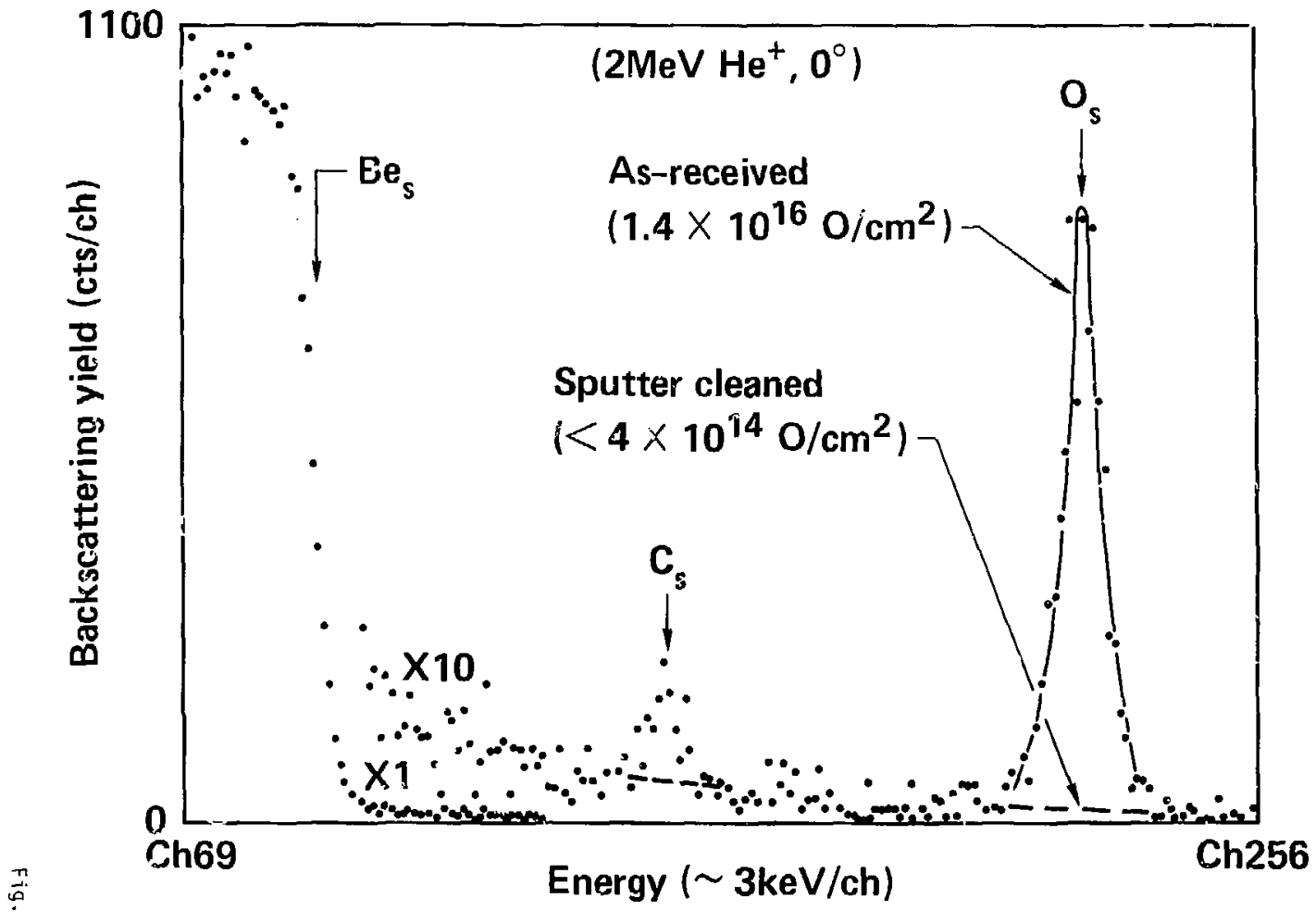




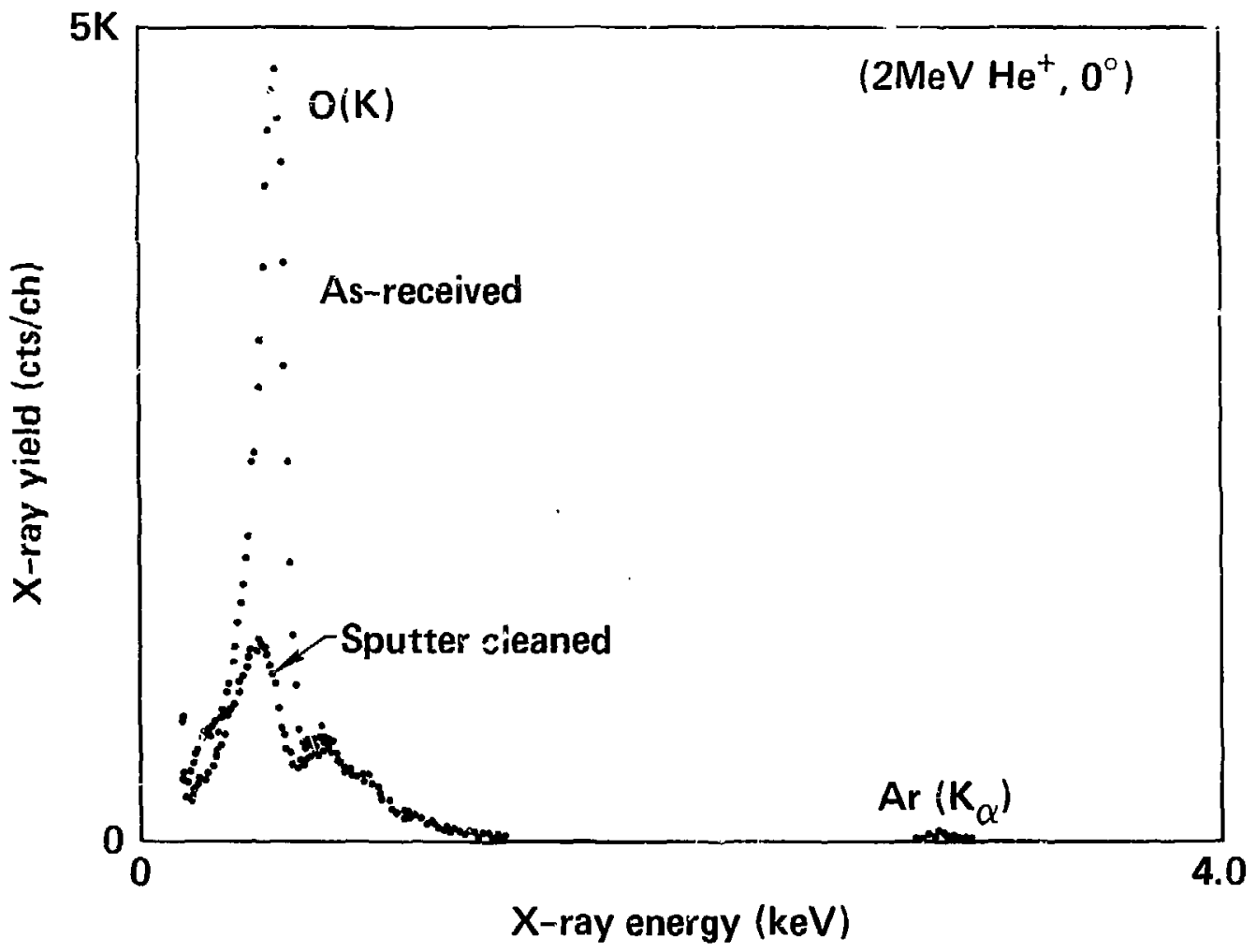

